\title{
JägerFriegslied Gqurra!
}

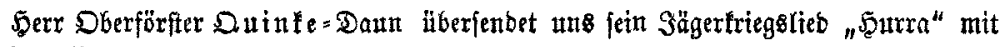

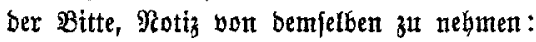

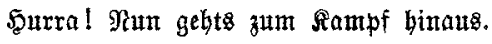

Mein Saijer rief zum Streit.

ADe, bu trautes Balbeshau,

Du meine berğ'ge Maib.

Sin iiberm Forft zum Iebtenmal

Da 5ifthorn ruft: Irara!

1: Utno wiebertaffts wobl taujentsmar:

Bum Tampfe auf, 5uxra!:|

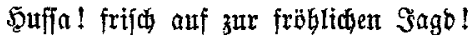

Mixit gilts bem eblen Seirid,

$\mathfrak{I n}$ beizerer, blut'ger Meännerjdlad,

Sa ziebe aut bie Birida;

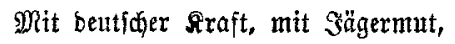

Эक̆ fämpfe fiegesfrob,

|: $\mathfrak{U}$ tho mag aud fließ̧en unjer $\mathfrak{B h a t ,}$

Sa) rufe Sorribo!:|

Mit Rübow millowerwegenter Singo

Эd) reite in ben $\mathfrak{I} 0 D$;

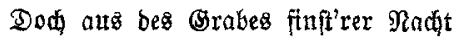

Bedt mid Das Mergenrot.

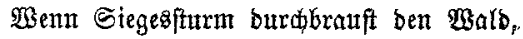
S由) Iaujd yom Grab empor.

|: Mein Salali entgegenjobaflt

Dem ftorzen Sägerforps. : ${ }^{1}$ )

\section{Ametgen.}

\section{forftliche Dorlefungen an oer Univerfität Wünchen.}

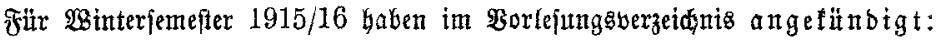

Brof. Dr. Endres: 1. Forftpolitif 5 ft. privatim; 2. Walbwertredintng unb forft=

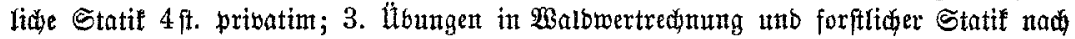

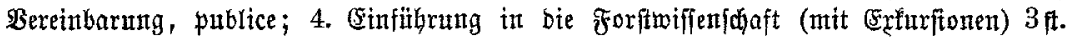

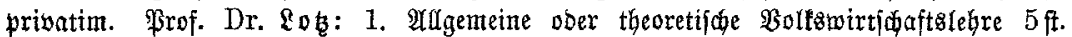

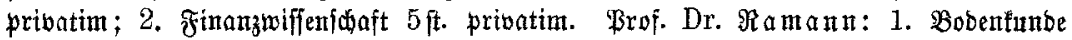

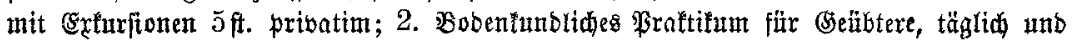
Galbtägliq, pribatiffine; 3. Aleines bobenfunblidez Braftifum 2 ft., publice. Prof. Dr. Freiberr von $\mathfrak{T}$ ubeuf: 1. Anatomie uno Pbyftologie ber Pflanzen 4 ft., pribatim; 2. Mitroffopiffes Praftifum 3ft., pribatifftme unb gratis. Frof. Dr. Salipfer:

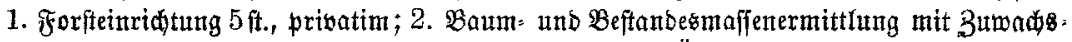

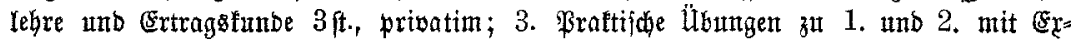

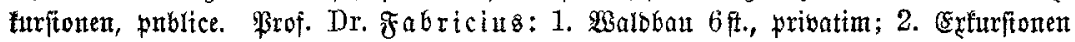

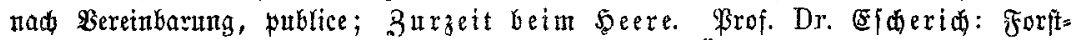

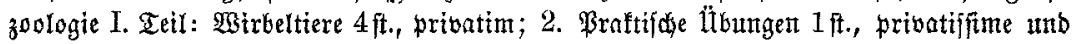

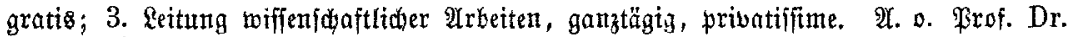

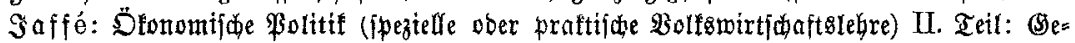
werbepolitif unb gewerbliche Arbetterfrage 2ft, priwatim. A. o. Frof. Dr. \&eongarb:

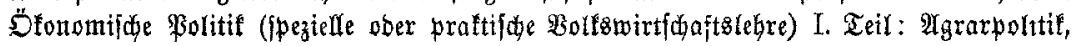
2 ft. priwatimt.

1) $\mathfrak{3 m}$ Verlag bon "Franfenland" (

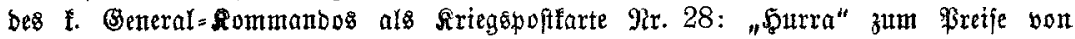
1000 staf. 28. - 100 sta. 3.- erifitent. 